\title{
Catalyst Evaluation and Scale-up Studies for Polyethylene Production
}

\author{
Vinit D. Makwana, G. Sivalingam, and Suketu M. Vakil
}

\begin{abstract}
Ziegler-Natta (Z-N) catalysts have been established as the catalysts of choice since the 1950s for low pressure production of polyethylene grades. These catalysts are mainly based on titanium with an organo-aluminium activator. The discovery of $\mathrm{MgCl}_{2}$ as a support for $\mathrm{Z}-\mathrm{N}$ catalysts led to a greatly increased catalyst activity. The phenomenon of replication in industrial gas phase polyethylene reactors necessitated the search for a support with high structural strength and an ability to be made in precisely tailored particle size distribution and morphology. $\mathbf{M g C l}_{2}$, although excellent in its chemical reactivity, was found wanting in structural strength and morphology control. These dual advantages were achieved when silica was used as a carrier/support for growing $\mathrm{MgCl}_{2}$ supported $\mathrm{Z}-\mathrm{N}$ catalysts. There are numerous patent references on the manufacture of highly active silica supported Z-N catalysts as well as a number of commercial standard silica supported Z-N catalysts as per specific needs. This paper describes the methodologies, basis and results of comparison of various standard silica-supported catalysts in a simple lab reactor set-up without the need for elaborate pilot plant trials. Three commonly available samples of silica supported catalyst were obtained and compared with benchmark Z-N catalyst. The catalysts were tested for their performance in both solvent phase polymerization reactor as well as gas phase fluidized bed reactor. The overall yield and quality of polymer were compared as well as the kinetic performance of each catalyst. A heat balance was generated around the gas phase reactor to arrive at kinetic profiles of catalyst activity. The prediction of scale-up behaviour of these catalysts based on lab reactor data and kinetic parameters has been discussed.
\end{abstract}

Index Terms-Fluidized bed reactor, scale-up, silica-supported Ziegler-Natta catalysts.

\section{INTRODUCTION}

Ziegler-Natta (Z-N) catalysts have been established as the catalysts of choice since the 1950s for low pressure production of polyethylene grades. These catalysts are mainly based on titanium with an organo-aluminium activator. As reaction progresses, the active site of the catalyst becomes encased in the growing polymer particle resulting in mass and heat transfer limitations and consequently, low catalyst activity. This led to the development of supported Z-N catalysts in the 70s with $\mathrm{MgCl}_{2}$ being the most widely employed support due to its chemical as well as physical nature [1]. Due to the phenomenon of replication in industrial gas phase polyethylene reactors, where the initial catalyst particle size distribution(PSD) and morphology is replicated in the final polymer particle, the PSD and morphology of the catalyst

Manuscript received July 4, 2013; revised October 5, 2013.

The authors are with the Polymer Technology Group, Reliance Industries Limited, 7B-GF, Reliance Corporate Park, Ghansoli, Navi Mumbai, 400701, India (e-mail: Sivalingam.gunasekaran@ ril.com). support becomes an important controlling factor in catalyst design and synthesis. A large particle size may lead to flow problems during pneumatic conveying of the polymer resin while a fine particle size may lead to excessive reaction rates leading to hot spots and also increasing the possibility of dust explosions. These hot spots are responsible for all kinds of fusion phenomenon which result in sheeting and agglomerates and lump formation. This led to the development of a third generation of silica supported/carried $\mathrm{Z}-\mathrm{N}$ catalysts which employ precisely tailored silica particles as a base to grow the $\mathrm{MgCl}_{2}$ supported Z-N catalyst. This allows maximum dispersion of the active sites while controlling morphology and PSD of the resulting catalyst particles. These catalysts usually yield densely packed polymer resin particles with higher apparent bulk density and have better attrition resistance. The uniform catalyst morphology and PSD reduces fines at source while the increased attrition resistance reduces fines generated inside the reactor. There are numerous patent references on the manufacture of highly active silica supported Z-N catalysts as well as a number of commercial standard silica supported Z-N catalysts as per specific needs [2]-[5].

This report describes the methodologies to compare the performance of various commonly available silica-supported catalysts. Three such commercial samples of silica supported catalyst were obtained for evaluation. The catalysts were evaluated for their performance in both solvent phase polymerization reactor as well as gas phase fluidized bed reactor. The catalysts' performance was compared against $\mathrm{MgCl}_{2}$ supported Z-N catalyst.

\section{EXPERIMENTAL}

A typical catalyst evaluation was done as per the following flowchart:

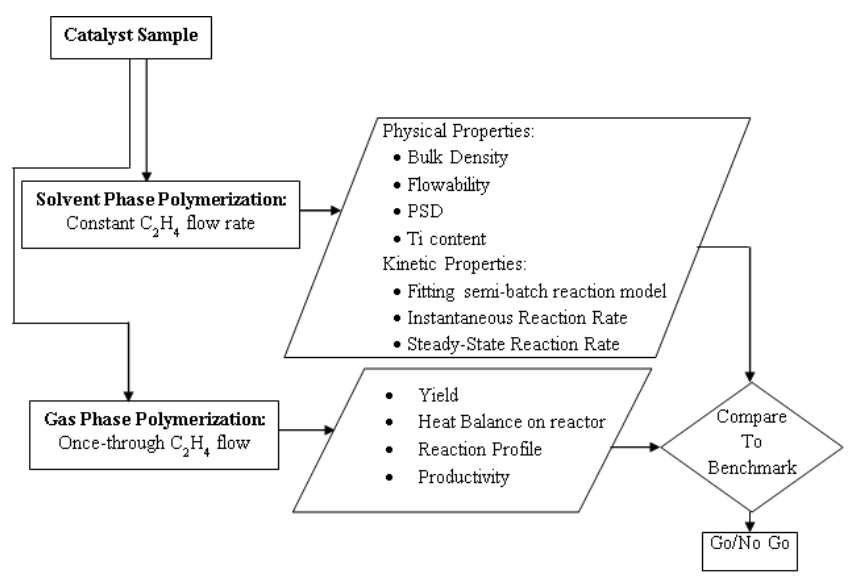

Fig. 1. Catalyst evaluation process flowchart 
The experimental investigation can be divided into four sections:

\section{A. Polymerization in Batch Stirred Tank Reactor}

\section{1) Characterization of polymer}

2) Gas phase polymerization in fluidized bed reactor

3) Modeling of catalyst activity

The detailed description of each is as follows:

\section{B. Polymerization in Batch Stirred Tank Reactor}

The polymerization tests were done in a stainless steel Büchi stirred tank reactor of $5 \mathrm{~L}$ volume. The reactor was equipped with a curved blade, radial turbine agitator (Büchi Type A61) magnetically coupled to an agitator motor. Various nozzles were available on the top flat end of the reactor for material addition, venting and temperature and pressure indication. The reactor contents can be discharged from the bottom through a ball valve to a container or directly to a filter-dryer. The reactor was jacketed with water being used as both heating and cooling medium. Hot water for heating was pumped from a Haake heating bath while raw water was used for cooling. The switching between hot and cold water was achieved by manually operated three-way valves.

A typical polymerization test was performed by charging 2 $\mathrm{L}$ hexane solvent to the reactor followed by the requisite quantity of 1.0 M tri-n-octylaluminium (TnOAl) solution as a cocatalyst in hexane. The TnOAl flask as well as the reactor were kept under continuous nitrogen purging for the entire time. The hexane and TnOAl was allowed to mix for 5 minutes while the catalyst was being weighed.

The dry catalyst powder was weighed into a glass sampling bottle inside a glove bag, with the weight determined by the Ti loading on the catalyst and the Ti loading required for that particular experiment. The bottle was sealed and withdrawn from the glove bag. The dry catalyst powder was then transferred from the glass sampling bottle to the reactor under nitrogen flushing. In case of catalyst slurry, as for the non-silica Z-N catalyst, the slurry was homogenized under nitrogen flow and the requisite quantity was pipetted and added to the reactor, similar to TnOAl addition. The reactor was boxed up and given a final purge with nitrogen and hot water circulation was started through the jacket. When the reactor temperature reached set temperature, hydrogen was added to the reactor such that pressure increased by 1.5 $\mathrm{kg} / \mathrm{cm}^{2} \mathrm{~g}$. After temperature stabilization, ethylene addition was initiated at a flowrate of $160 \mathrm{~g} / \mathrm{h}$ which was precisely controlled using a Bronkhörst mass flow indicator and controller. The gas diffused into the solution phase followed by reaction to form polymer product. If the consumption rate of ethylene is higher than the ethylene feed rate, a decrease in reactor pressure was noted while in the reverse case, an increase in reactor pressure was observed. The addition was continued for $3 \mathrm{~h}$ at constant feed rate and the pressure profile of the reactor was recorded. The polymerization reaction being highly exothermic, an increase in the reactor temperature was also observed. The temperature was controlled between $69^{\circ} \mathrm{C}$ to $71^{\circ} \mathrm{C}$ by controlling the heating bath temperature. At the end of $3 \mathrm{~h}$, ethylene feed was stopped and the reactor was cooled to room temperature. The reactor was vented to atmosphere and flushed with nitrogen to remove traces of any dissolved ethylene. The reaction slurry was discharged from the bottom ball valve into a container followed by washing with hexane. The hexane was dried under nitrogen flushing to yield a dry polymer powder. The dry polymer powder was evaluated for physical properties like bulk density, flowability, morphology and particle size distribution(PSD).

\section{Characterization of polymer}

\section{1) Bulk density}

The untapped bulk density of polymer powder was measured using a standard metal beaker of $95 \mathrm{~mL}$ volume. The polymer powder was filled into the beaker without any tapping and the top surface of the powder was smoothened to fill the beaker exactly to the brim with level exactly parallel to the horizontal. The resultant polymer weight was determined and divided by 95 to obtain the bulk density (BD) of the polymer powder in $\mathrm{g} / \mathrm{ml}$

\section{2) Flowability}

Flowability of the polymer powder was measured on an empirical scale of +3 (easiest to flow) to -3 (difficult to flow or no flow) based on the ability of polymer powder to flow out from a truncated inverted cone of progressively increasing diameter. The cones had a constant top diameter of $65 \mathrm{~mm}$ as well as a constant angle of inclination of $30^{\circ}$. The base opening diameter was varied from $10 \mathrm{~mm}$ to $30 \mathrm{~mm}$ by varying the length of truncation of the cone. The cones were made of stainless stell and with a smooth internal finish to prevent rusting and corrosion from hindering the flow of particles. Thus powder flowing readily from a $10 \mathrm{~mm}$ base diameter (smallest) cone was classified as having +3 flowability. If the powder flowed through this opening only after hitting the cone once with a rubber mallet, then the flowability was classified as +2 . If the powder flowed easily or with a mallet hit from a cone with $15 \mathrm{~mm}$ base diameter, the flowability was classified as +1 . The flowability was classified as 0 if the polymer powder flowed readily or after a mallet hit from a cone with $20 \mathrm{~mm}$ base diameter. Similarly, if the powder flowed easily or with a mallet hit from a cone with $25 \mathrm{~mm}$ base diameter, the flowability was classified as -1 . The biggest cone with $30 \mathrm{~mm}$ base diameter was used to classify powder flowability as -2 in case of ready flow or flow with a mallet hit or -3 in case of no flow.

\section{3) Particle size distribution (PSD)}

The PSD of powder sample was determined using the principle of diffraction of light. In a Microtrac S3500 instrument, polymer powder particles were sprayed through the laser beam path which caused diffraction of the laser light at different angles depending on the size of the particle obstructing the beam path. The diffracted light was focussed to a detector using lens and after adequate signal processing using a PC program an output in terms of Average Particle Size(APS) in micrometers was generated. The computer program also determined the percentile of particles below $250 \mu \mathrm{m}$ size, below $80 \mu \mathrm{m}$ size and below $50 \mu \mathrm{m}$ size to complete the PSD measurement.

\section{4) Ti content measurement by XRF}

A disc of polymer was made by cold-pressing $7 \mathrm{~g}$ of polymer powder. The disc dimensions were $45 \mathrm{~mm}$ diameter $\times 5 \mathrm{~mm}$ thickness. The disc was loaded onto an Oxford 
Instruments MDX1000 X-Ray Fluorescence spectrometer. The spectrometer measured characteristic X-ray fluorescence emissions of elements like $\mathrm{Al}, \mathrm{Ti}, \mathrm{Cl}$ and $\mathrm{Si}$ and correlated them with calibration measurements done earlier to yield a concentration value of these specific elements. This concentration was used to determine the final $\mathrm{Al}$ : Ti ratio and yield of the polymer in terms of $\mathrm{g}$ of polymer formed per mmol of $\mathrm{Ti}$.

\section{5) Imaging by polarized light microscopy}

The morphology of the polymer formed was investigated under a polarized light microscope. A small quantity of the polymer was spread on a clean, dry glass slide and held under the microscope objective. The resultant images were captured on a CCD camera and stored digitally.

\section{Gas Phase Polymerization in Fluidized Bed Reactor}

The gas phase polymerization was performed in a lab reactor, which is schematically shown below:

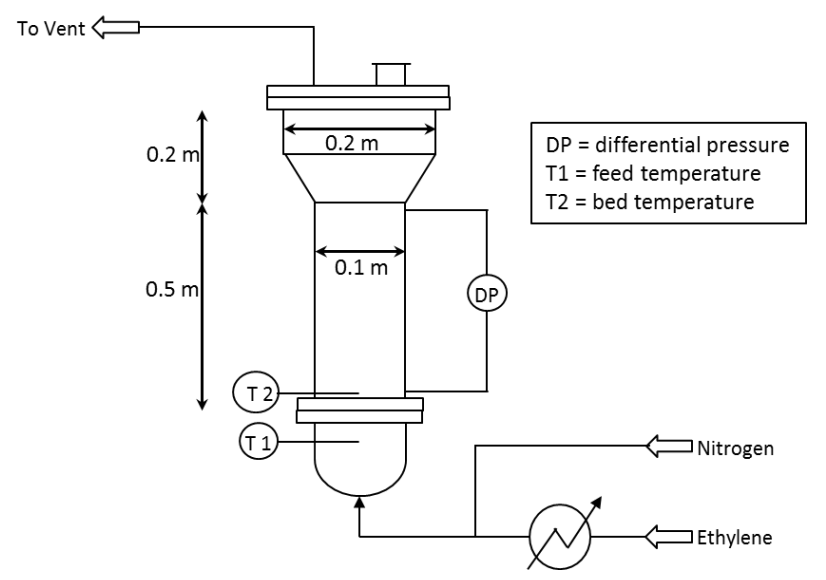

Fig. 2. Laboratory gas phase fluidized bed reactor

$200 \mathrm{~g}$ of virgin polymer powder was used as a seed bed and was charged to the reactor. The seed bed was unstabilized polymer resin of average particle size in the range of $840-$ $900 \mu \mathrm{m}$. The seed bed was purged and degassed of any physisorbed moisture, $\mathrm{CO}_{2}$ and $\mathrm{O}_{2}$ by purging with hot ethylene at atleast $70^{\circ} \mathrm{C}$ for atleast $4 \mathrm{~h}$. The seed bed was cooled down and purged with nitrogen to remove all traces of hydrocarbon. After this purging, the reactor top nozzle was opened, while maintaining a positive pressure of nitrogen, and required quantity of co-catalyst was added. The co-catalyst used for all trials was a $1.0 \mathrm{M}$ solution of tri-n-octylaluminium (TnOAl) in hexane. The required quantity of catalyst - either in slurry form or as a dry powder was charged to the reactor from the top nozzle, again while maintaining positive pressure of nitrogen in the reactor. The catalyst was weighed into a catalyst flask inside a glove bag with a nitrogen atmosphere and the catalyst flask was sealed with nitrogen. The catalyst flask had a side-nozzle with a 3-way valve from where the flask itself could be purged with nitrogen. At the moment of addition of catalyst to the reactor, the catalyst flask was also maintained under positive nitrogen pressure from the side nozzle. The nitrogen pressure prevented poisons from contacting the active sites as well as providing faster transfer due to pressure differential. After catalyst transfer, the reactor was boxed-up and purged with nitrogen for 15 minutes. This allowed complete mixing of the seed bed, co-catalyst and catalyst.

The nitrogen was stopped and ethylene feed was started to the reactor. The reactor outlet gases were throttled until pressure in the reactor increased to $6 \mathrm{~kg} / \mathrm{cm}^{2} . \mathrm{g}$, which was the operating pressure for all experiments. The feed gas stream was routed through a feed pre-heater to preheat feed gas so as to achieve required temperature inside the reactor. The operating temperature was typically in the $70^{\circ} \mathrm{C}$ to $85^{\circ} \mathrm{C}$ range. Once the desired operating pressure and temperature was achieved, the experiment was conducted in this steady-state condition for $2 \mathrm{~h}$ before shutting off the ethylene feed and cooling down the reactor. The reactor was purged with nitrogen again after cooling down to ensure hydrocarbon-free atmosphere before opening the reactor for product withdrawal.

\section{E. Modeling of Catalyst Activity}

The polymer formed at the end of reaction was weighed and the space-time yield (STY), defined as the polymer produced per unit volume of reactor per hour of reaction, was calculated. The productivity was measured as the polymer formed per weight of catalyst charged. This number was typically reported as MT of polymer formed per $\mathrm{kg}$ of catalyst charged. Another commonly used norm of productivity was polymer formed per mmol of $\mathrm{Ti}$ charged which gave a measure of the Ti utilization of the catalyst.

The above calculations of total yield and STY gave the scenario at the end of a run by measuring the total polymer formed.The profile of ethylene consumption rate was another important parameter which cannot be directly calculated using measured variables such as temperatures across grid, ethylene flow and reactor pressure. Ethylene consumption rate was derived from energy balance around the reactor and performance of various standard catalysts was evaluated. Steady state energy balance for the vent test reactor was written as follows

$$
Q_{\text {inlet }}+Q_{\text {reaction }}=Q_{\text {exit }}+Q_{\text {loss }}+Q_{\text {fusion }}
$$

Enthalpy of the ethylene feed stream can be given as,

$$
Q_{\text {inlet }}=m_{i} C p_{i} T_{i}
$$

where, $m_{i}=$ ethylene feed rate, $\mathrm{kg} / \mathrm{h}$

$C p_{i}=$ heat capacity of ethylene at feed conditions, $\mathrm{kcal} / \mathrm{kg} . K$

$T_{i}=$ grid bottom temperature, ${ }^{\circ} \mathrm{C}$

Considering steady state ethylene mass balance,

$$
m_{i}=m_{o}+m_{r}
$$

where, $m_{o}=$ exit flow rate of ethylene, $\mathrm{kg} / \mathrm{h}$

$m_{r}=$ ethylene consumption OR polymer production rate, $\mathrm{kg} / \mathrm{h}$

Enthalpy of reaction can be given as,

$$
Q_{r}=m_{r} \cdot \Delta H_{r}
$$

where, $\Delta H_{r}=$ heat of reaction $=857 \mathrm{kcal} / \mathrm{kg} P E$ formed [6] Assuming that the reaction zone was completely 
well-mixed and hence grid top temperature was equal to the reactor exit temperature, enthalpy of exit stream can be given as

$$
Q_{o}=m_{o} \cdot C p_{o} \cdot T_{o}+m_{r} \cdot C p_{o P E} \cdot T_{o}+m_{\text {seed }} \cdot C p_{o P E} \cdot\left(T_{o i}-T_{o i-1}\right)
$$

where, $C p_{o}=$ heat capacity of ethylene at reactor exit conditions, $\mathrm{kcal} / \mathrm{kg} . K$

$C p_{o P E}=$ heat capacity of polymer, $\mathrm{kcal} / \mathrm{kg} . K$

Heat loss from the system is due to radiation and convection from insulated and uninsulated surface.

Enthalpy of fusion can be given as,

$$
Q_{\text {fusion }}=\left(m_{r}+m_{\text {seed }}\right) \cdot \Delta H_{\text {fusion }}
$$

where, $\Delta H_{\text {fusion }}=$ heat of fusion $=58.6 \mathrm{kcal} / \mathrm{kg}$ [7]

Thus by combining the above, the equation for ethylene consumption can be derived as,

$$
m_{r}=\frac{m_{o} C p_{o} \cdot T_{o}+Q_{\text {loss }}+m_{\text {seed }} \cdot\left[C p_{o P E} \cdot\left(T_{o i}-T_{o i-1}\right)+\Delta H_{\text {fusion }}\right]}{C p_{i} \cdot T_{i}+\Delta H-C p_{o P E} \cdot T_{o}-\Delta H_{\text {fusion }}}
$$

The heat loss term from the above equation can be neglected as heat lost from insulated cylindrical part of the reactor is negligible. Hence, final equation can be given as,

$$
m_{r}=\frac{m_{o} C p_{o} \cdot T_{o}+m_{\text {seed }} \cdot\left[C p_{o P E} \cdot\left(T_{o i}-T_{o i-1}\right)+\Delta H_{\text {fusion }}\right]}{C p_{i} \cdot T_{i}+\Delta H-C p_{o P E} \cdot T_{o}-\Delta H_{\text {fusion }}}
$$

The overall yield estimated by the above equation was reasonably accurate with experimental observation except in cases where polymer lumps were observed. This indicated a much higher local temperature than that measured by the temperature indicator which led to sintering and agglomeration. In such cases a temperature correction was applied to reactor temperature to rationalize predicted and measured yield.

\section{RESULTS AND DISCUSSION}

The characteristics of catalysts used in the current study are listed below in Table I.

TABLE I: CATALYST PROPERTIES

\begin{tabular}{lcccc}
\hline \hline Catalyst $\rightarrow$ & $\begin{array}{c}\text { Benchmark } \\
\text { Catalyst }\end{array}$ & $\begin{array}{c}\text { Catalyst } \\
\text { A }\end{array}$ & $\begin{array}{c}\text { Catalyst } \\
\text { B }\end{array}$ & $\begin{array}{c}\text { Catalyst } \\
\text { C }\end{array}$ \\
\hline $\mathrm{d}_{50}, \mu \mathrm{m}$ & 37 & 34 & 48 & 46 \\
Ti content, w/w\% & 8.0 & 1.4 & 1.1 & 1.1 \\
$\begin{array}{l}\text { Silica supported } \\
\begin{array}{l}\text { Morphologically - } \\
\text { controlled }\end{array}\end{array}$ & No & Yes & Yes & Yes \\
\hline \hline $\begin{array}{l}\text { Morphologically - } \\
\text { controlled }\end{array}$ & No & Yes & Yes & Yes \\
\hline \hline
\end{tabular}

Catalyst A has a similar particle size as the benchmark catalyst while Catalysts $\mathrm{B}$ and $\mathrm{C}$ have a larger particle size. The Ti loading for silica supported catalysts is much lower than the benchmark catalyst, although the $\mathrm{Ti}$ is much more dispersed on the silica supported catalysts as compared to the benchmark catalyst.

\section{A. Solvent Phase Polymerization Results}

The physical properties of the formed polymer powder were measured and tabulated below in Table II.
TABLE II: POLYMER PHYSICAL PROPERTIES

\begin{tabular}{lcccc}
\hline \hline Catalyst $\rightarrow$ & $\begin{array}{c}\text { Benchmark } \\
\text { Catalyst }\end{array}$ & $\begin{array}{c}\text { Catalyst } \\
\text { A }\end{array}$ & $\begin{array}{c}\text { Catalyst } \\
\text { B }\end{array}$ & $\begin{array}{c}\text { Catalyst } \\
\text { C }\end{array}$ \\
\hline $\begin{array}{l}\text { Bulk Density, g/cc } \\
\text { Flowability }\end{array}$ & 0.28 & 0.39 & 0.32 & 0.22 \\
& +2 & +3 & +3 & +3 \\
\hline PSD: & & & & \\
APS, $\mu \mathrm{m}$ & 234 & 115 & 158 & 166 \\
< $250 \mu \mathrm{m}$, & 54.8 & 97.5 & 80.6 & 84.3 \\
percentile & & & & \\
< $80 \mu \mathrm{m}$, & 6.5 & 16.6 & 15.4 & 22.8 \\
percentile & & & & \\
$<50 \mu \mathrm{m}$, & 1.7 & 1.7 & 4.8 & 15.8 \\
percentile & & & & \\
\hline XRF Results: & 839 & 821 & 1173 & 1515 \\
Al, ppm & 1293 & 246 & 205 & 218 \\
Ti, ppm & -- & 2.55 & 3.09 & 2.45 \\
Si, wt\% & & & & \\
\hline \hline
\end{tabular}

The magnified images of these polymer particles taken by a polarized light microscope at $10 x$ magnification were presented below in Fig. 3. A comparison of the polymer formed using benchmark $\mathrm{MgCl} 2$ supported $\mathrm{ZN}$ catalyst and a representative sample of silica supported catalyst can be easily made. The unsupported benchmark catalyst polymer exhibited a wide size variation with irregular shapes, while the silica supported catalyst polymer showed uniform spherical shapes with a narrower particle size distribution. These images corroborated the morphology - control achieved with silica supported catalysts.
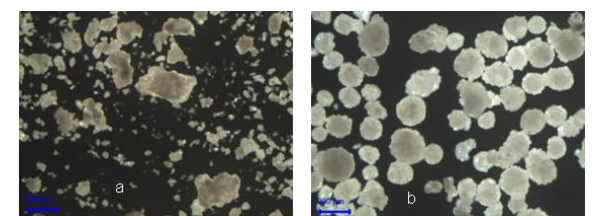

Fig. 3. Polarized light microscopy images of polymer with a) benchmark catalyst, b) silica supported catalyst

The pressure profiles during polymerization reactions for various catalysts were measured and plotted as shown in Fig. 4.

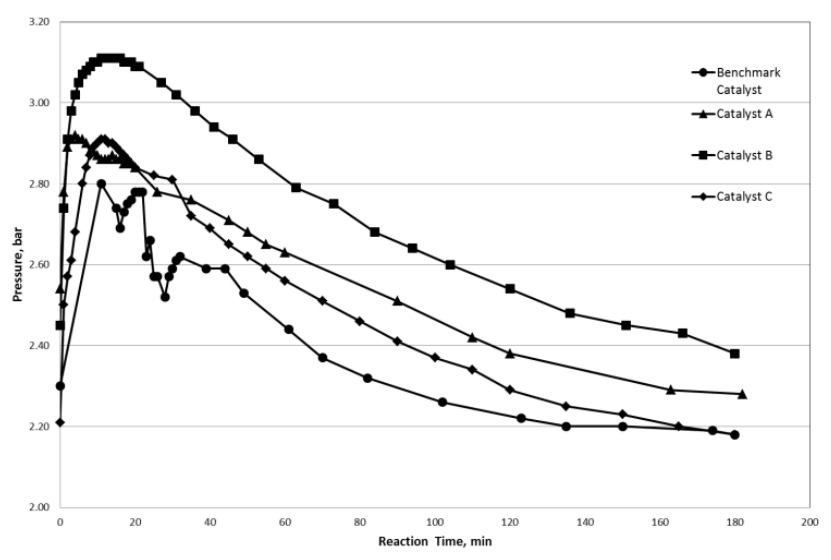

Fig. 4. Pressure profiles during solvent phase polymerization

The pressure build up in the reactor was the result of the differential between the ethylene feed rate and ethylene consumption rate [8]. Thus the rate of consumption of ethylene was determined from the pressure profile during the reaction. Since ethylene was added to the reactor in a 
semi-batch manner, the conversion was defined as an instantaneous conversion as well as an overall conversion.

Instantaneous conversion at time $t$ is:

$$
x(t)=\frac{\text { ethylene fed }- \text { ethylene } \overrightarrow{\text { in head space }}}{\text { ethylene } \mathrm{fed}}
$$

Overall conversion:

$$
X=x(t) . \frac{[(\text { ethylene addition } \overrightarrow{\text { rate }}) .(t)]}{\text { Total } \overrightarrow{\text { ethylene }} \overrightarrow{\text { added }}}
$$

Overall rate of polymerization:

$$
R_{p}=\frac{d X}{d t}=\frac{\text { ethylene addition } \overrightarrow{\text { rate }}}{\text { Total ethylene } \overrightarrow{\text { added }}} \cdot\left[t \cdot \frac{d x}{d t}+x\right]
$$

The overall polymerization rates are Fig. 5 below.

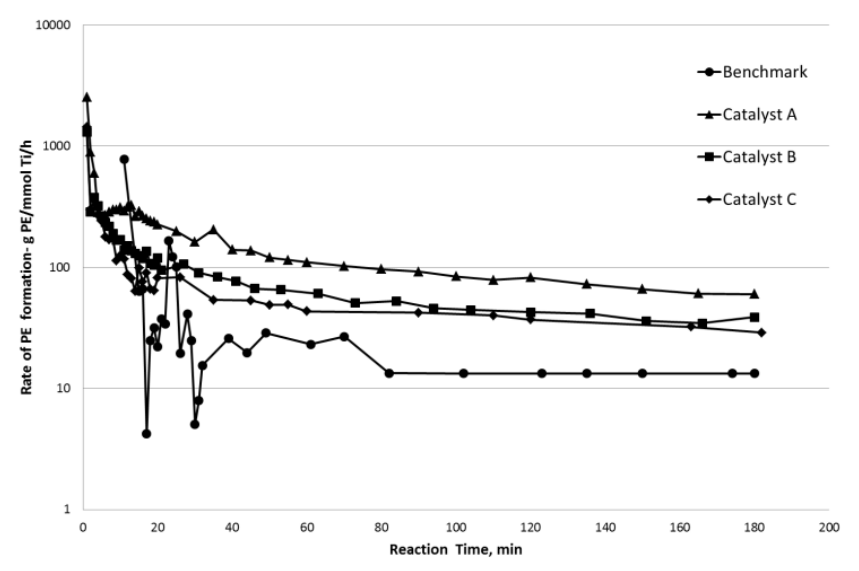

Fig. 5. Overall rate of polymerization - various catalysts

TABLE III: STEADY-STATE POLYMERIZATION RATES

\begin{tabular}{lcccc}
\hline Catalyst $\rightarrow$ & $\begin{array}{c}\text { Benchmark } \\
\text { Catalyst }\end{array}$ & $\begin{array}{c}\text { Catalyst } \\
\text { A }\end{array}$ & $\begin{array}{c}\text { Catalyst } \\
\text { B }\end{array}$ & $\begin{array}{c}\text { Catalyst } \\
\mathrm{C}\end{array}$ \\
\hline $\begin{array}{l}\text { Instantaneous } \\
\text { Maximum Rate, } \\
\text { g/mmol Ti/h }\end{array}$ & 775 & 2531 & 1306 & 1429 \\
$\begin{array}{l}\text { Steady-state rate, } \\
\text { g/mmol Ti/h }\end{array}$ & 13.2 & 78.2 & 43.4 & 37.2 \\
$\begin{array}{l}\text { Overall average } \\
\text { rate, } \\
\text { g/mmol Ti/h }\end{array}$ & 51.0 & 135.3 & 73.0 & 61.3 \\
\hline \hline
\end{tabular}

Each of the catalysts, including benchmark catalyst, showed a high initial rate which rapidly decayed into a flat, steady-state polymerization rate. The level of this flat steady-state activity determined the final productivity of the catalyst. As seen from Fig. 5 above, all the silica supported catalysts had a steady-state polymerization rate higher than that for the benchmark catalyst.

The accessibility of $\mathrm{Ti}$ active sites in silica supported catalysts was higher due to the dispersion of these sites on silica support which was manifested as a higher molar rate. Amongst the silica supported catalysts, catalyst A with smaller particle size had a higher molar rate than the catalysts $\mathrm{B}$ and $\mathrm{C}$ which had larger particle sizes. This again indicated the importance of $\mathrm{Ti}$ dispersion and accessibility.
Contrararily, the catalysts B and C have the same Ti loading and similar particle size, but their rates showed appreciable differences. This differences could be attributed to the method of dispersion of Ti on the silica support. Since the commercial catalysts are vendor supplied, this information was proprietary knowledge and it was difficult to conclude further.

\section{B. Gas Phase Polymerization Results}

The Ti loading for silica supported catalysts was required to be reduced to a quarter of that for unsupported benchmark catalyst in order to maintain similar Space Time Yield (STY). Since the product withdrawal from the gas phase reactor was done only at the end of run, it was difficult to differentiate between the polymer formed during steady state operation and during non-steady state operation. The time required to achieve steady-state operation being almost equal to the actual steady-state operation time, this differentiation was necessary to accurately estimate STY and productivity. The differentiation was achieved by performing a heat balance on the reactor to estimate polymer formation rate. The output of these heat balance calculations was plotted below in Fig. 6 .

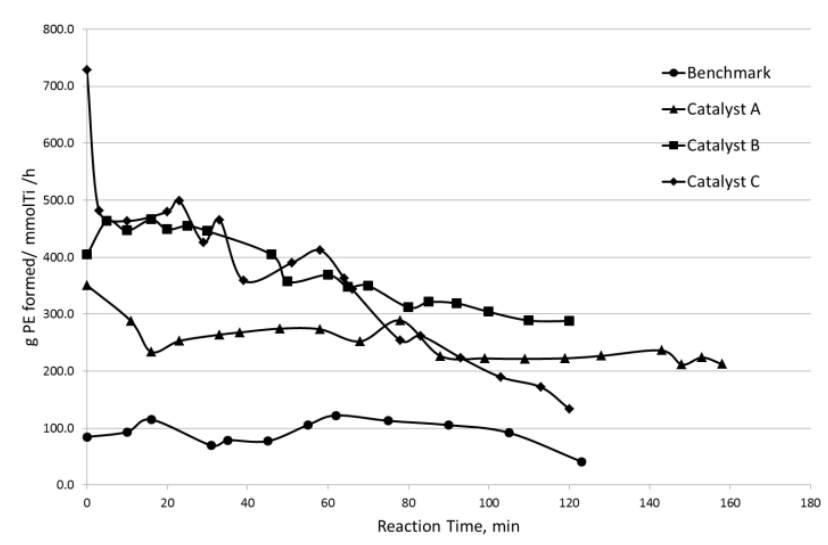

Fig. 6. Polymer formation rate in gas phase reactor - various catalysts

Apart from the productivity and product characteristics, another important criterion in the catalyst selection process was the controllability of reaction. In the above fig., Catalyst A exhibited an ethylene consumption rate approximately 2.5 times higher than that of benchmark catalyst. There was an initial peak with sharp drop in ethylene consumption rate for the first 20 minutes of reaction time after which the profile remained reasonably flat. The activity decay was also very gradual over 160 minutes of reaction time. The profile is reasonably flat, except for the initial sharp drop, indicating a smooth, easily-controlled reaction. Catalyst B showed a slightly higher initial rate although the steep drop after 20 minutes of reaction time was not repeated. The decay in ethylene consumption rate was however much steeper with the rate declining by $35 \%$ over $2 \mathrm{~h}$ of reaction time. Catalyst $\mathrm{C}$ showed an extremely high initial reaction rate which dropped precipitously in the first $3-5$ minutes of reaction time. This was followed by an equally steep decay where activity declined by $350 \%$ over 120 minutes of reaction time. This high activity - fast decay reaction profile would lead to temperature control issues and also hot spots and lump formation in the reactor.

The polymer formation profiles were used to plot a cumulative polymer formation versus reaction co-ordinate 
plot, which was then used for yield and productivity calculations. These results were plotted in Fig. 7 below.

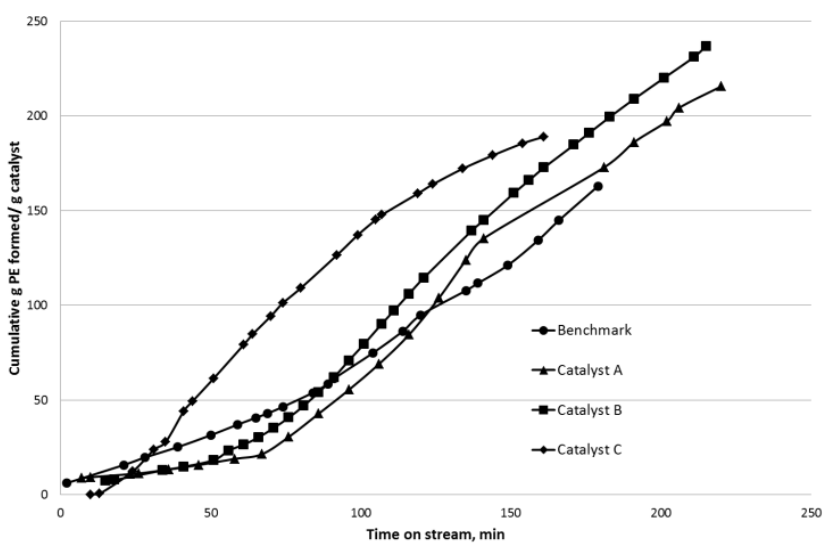

Fig. 7. Productivity rates $-\mathrm{w} / \mathrm{w}-$ various catalysts

The productivity calculations were done based on these plots and were tabulated as below in Table IV.

TABLE IV: YIELD AND PRODUCTIVITY - GAS PHASE POLYMERIZATION, VARIOUS CATALYSTS

\begin{tabular}{lcccc}
\hline \hline Catalyst $\rightarrow$ & $\begin{array}{c}\text { Benchmark } \\
\text { Catalyst }\end{array}$ & $\begin{array}{c}\text { Catalyst } \\
\text { A }\end{array}$ & $\begin{array}{c}\text { Catalyst } \\
\text { B }\end{array}$ & $\begin{array}{c}\text { Catalyst } \\
\text { C }\end{array}$ \\
\hline $\mathrm{STY}, \mathrm{kg} / \mathrm{m}^{3} / \mathrm{h}$ & 48.5 & 39.1 & 46.6 & 43.0 \\
$\begin{array}{l}\text { Productivity, } \\
\text { g PE/g catalyst/h }\end{array}$ & 37.1 & 62.0 & 59.6 & 40.8 \\
$\begin{array}{l}\text { Productivity, } \\
\text { g PE/mmol Ti/h }\end{array}$ & 50.1 & 212.1 & 257.2 & 184.2 \\
\hline \hline
\end{tabular}

As anticipated, the productivity in molar basis of $\mathrm{Ti}$ was signigficantly higher for the silica supported catalysts as compared to the benchmark catalyst. This was due to the greater dispersion of $\mathrm{Ti}$ on the silica support leading to greater accessibility to active sites. The weight based productivity was also higher by $10 \%-67 \%$ with reference to benchmark catalyst.

\section{CONCLUSION}

A simple lab reactor based methodology for evaluating polymerization catalysts was presented. A solvent phase polymerization experiment was used to generate steady state reaction rate data while a once-through lab fluidized bed reactor was used to measure gas phase polymerization rates and productivity. The physical properties of polymer formed in solvent phase polymerization, such as bulk density and flowability, could be used to gauge the efficacy of catalyst in improving polymer characteristics for downstream processing. The morphology of polymer obtained from silica supported catalysts exhibited a uniform spherical shape and much narrower PSD. The instantaneous, steady-state and overall average reaction rates in solvent phase polymerization were all higher for silica supported catalysts when compared to the benchmark, non-silica Z-N catalyst. Since the productivity of the benchmark catalyst in a commercial reactor was known due to it being used in a commercial scale reactor, a scale-up factor from the lab once-through reactor to commercial scale was easily found. The same factor can be used to project commercial scale productivities of any of the catalysts tested. These techniques represent a quick method of evaluating standard commercial catalyst or in-house developed catalysts and predicting their scale-up behaviour.

Another important outcome of these experiments was the correlation between catalyst performance and catalyst characteristics. Apart from the rate, physical properties like bulk density and particle size distribution of the product can be correlated with the catalyst physical and chemical characteristics to generate models of particle growth and reactivity. These can be used to elucidate the mechanism of action of current catalysts as well as perform better design of newer catalysts.

\section{ACKNOWLEDGMENT}

The work presented in this report was performed at the Quality Assurance Laboratory, Nagothane Manufacturing Division, Reliance Industries Limited. We would like to wholeheartedly thank Mr. M. T. Bhosale, Mr. P. G. Sheth and all the lab personnel for their support and assistance.

\section{REFERENCES}

[1] D. B. Malpass, Introduction to Industrial Polyethylene: Properties, Catalysts and Processes, New Jersey, US, Wiley, 2010, ch. 3, pp. 33-44.

[2] C. Chamla and C. Daire, "Supported Polyolefin Catalyst for the (Co-) polymerization of Ethylene in Gas Phase," U. S. Patent 5124 296, Jun 23, 1992.

[3] Q. Wang, "Ziegler-Natta Catalyst for High Temperature Polymerization," W. O. Patent 2008/022430, Feb 28, 2008.

[4] K. Gao, D. Liu, W. Chen, G. Fan, X. Lu, J. An et al., "Catalyst Component for Ethylene Polymerization, a Process for Preparing thereof and Catalyst Comprising the same," U. S. Patent 2004/127349, Jul 1, 2004.

[5] E. M. Stacy and K. S. Collins, "Catalyst and Polymerization of Olefins," E. Patent 0696 600, Feb 14, 1996

[6] S. X. Zhang, N. K. Read, and W. H. Ray, "Runaway Phenomena in Low-Density Polyethylene Autoclave Reactors," AICHE J., vol. 42, no. 10, pp. 2911-2925, Oct 1996.

[7] INEOS Datasheets. [Online]. Available: http://www.ineos.com/Global/Olefins and Polymers USA/Products/technical information/Typical Engineering Properties of HDPE.pdf

[8] S. Sajjadi and B. W. Brooks, "Semibatch Emulsion Polymerization Reactors," Chem. Eng. Sci., vol. 55, no. 20, pp. 4757-4781, Oct. 2000.

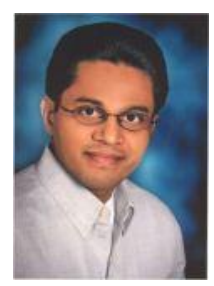

Vinit D. Makwana is a senior technologist in the Polymer Technology Group with Reliance Industries Limited, Navi Mumbai, India. He had received his B. Chem. Engg. degree from the University Department of Chemical Technology (UDCT), Mumbai, India and $\mathrm{Ph}$.D. from the University of Connecticut, Storrs, USA. After completing his doctorate, he worked as a research associate with the Fritz Haber Institute of the Max Planck Society, Berlin, Germany in the field of heterogeneous catalysis. Prior to Joining Reliance in 2012, he worked for SI Group. He works on research problems of catalysis, process development and scale-up in the polyolefins arena.

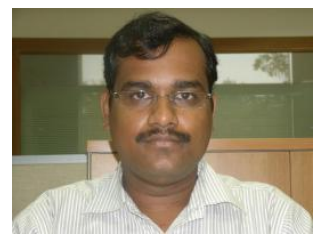

G. Sivalingam is an assistant vice president in Reliance Technology Group at Reliance Industries Limited. $\mathrm{He}$ has earned $\mathrm{PhD}$ in Chemical Engineering from Indian Institute of Science, Bangalore and $\mathrm{M}$ Tech in Chemical Engineering from Indian Institute of Technology, Kanpur. He was awarded with 
various National (by INAE and IIChE) and Institute Level Awards (by IISc, Univ of Madras) for his contributions. He has published more than 30 refereed articles which received 1400 citations and h-index of 18. Since joining Reliance in 2006, he has been working on various initiatives in Research \& Technology Development, Process Modelling, Process Debottlenecking and Polymer Nanocomposites. He has joined Reliance from John F Welch Technology Centre, GE. He is a certified Green Belt in Six Sigma and a reviewer for journals.

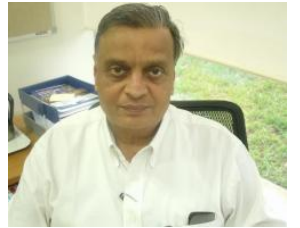

Suketu M. Vakil is a group president in Polymer Technology Group of Reliance Industries Limited, India. He holds B. ChE degree in Chemical Engineering. He has nearly 40 years of experience in polymer field including 27 years in Reliance. He has led Technology, Project, Operation and R\&D in various capacities during his long tenure. 